\title{
Blood blister-like aneurysms of the internal carotid artery
}

\author{
Mildred Arteaga Soto', Eberval Gadelha Figueiredo², \\ Maria Luana Carvalho Viegas ${ }^{3}$, Manoel Jacobsen Teixeira ${ }^{4}$
}

\begin{abstract}
Blood blister-like aneurysms (BBA) originate at non-branching sites of the internal carotid artery (ICA), these vascular lesions are rare and constitute approximately $1 \%$ of all intracranial aneurysms. They are small, with extremely fragile walls and a poorly defined broad-based neck. BBA tend to have a precipitous clinical course, enlarging rapidly, these have been associated with significant morbidity and mortality including rebleeding, regrowth, and ischemic complications; therefore their diagnosis is essential for proper management and depends of its high suspicion and careful evaluation of computed tomography angiogram (CTA) and digital substraction angiography (DSA). Various surgical and endovascular strategies have been attempted for these lesions, but the definitive treatment is controversial even. This paper attempts to describe the clinicopathological features as well as elements important for diagnosis and treatment.
\end{abstract}

\section{KEYWORDS}

Intracranial aneurysm, carotid artery diseases, subarachnoid hemorrhage, therapeutic.

\section{RESUMO}

Aneurismas das porções não ramificadas da artéria carótida interna

Os aneurismas das porções não ramificadas da artéria carótida interna (BBA, da sigla em inglês) são lesões vasculares raras e constituem cerca de $1 \%$ de todos os aneurismas intracranianos. Eles são pequenos, com paredes extremamente frágeis e um colo mal definido com base ampla. Os BBA tendem a ter curso clínico rápido e têm sido associados com morbidade e mortalidade significativas, incluindo ressangramento e complicações isquêmicas, por isso seu diagnóstico é essencial para o bom tratamento e depende de elevada suspeição e cuidadosa análise da angiografia por tomografia computadorizada e por subtração digital. Várias estratégias cirúrgicas e endovasculares têm sido tentadas para essas lesões, mas o tratamento definitivo é controverso. Este artigo tenta descrever as características clinicopatológicas, bem como elementos importantes para o diagnóstico e tratamento dessa entidade patológica.

\section{PALAVRAS-CHAVE}

Aneurisma intracraniano, doenças das artérias carótidas, hemorragia subaracnóidea, terapêutica.

1 Resident Honorio Delgado Hospital, National University of San Agustin, Arequipa Peru.

2 Head of Neurovascular Group and Supervisor of Division of Neurosurgery of Hospital das Clínicas, University of São Paulo (USP), São Paulo, SP, Brazil.

3 Medical student, Federal University of Pará (UFPA), Belém, PA, Brazil.

4 Chairman, Division of Neurosurgery Hospital das Clínicas, USP, São Paulo, SP, Brazil. 


\section{Introduction}

Cerebral aneurysms causing subarachnoid hemorrhage (SAH) usually occur at arterial bifurcations or branching sites. However $0.3 \%$ to $1 \%$ of all intracranial aneurysms or $0.9 \%$ to $6.5 \%$ of aneurysm of the internal carotida internal (ICA) arise at non-branching sites. ${ }^{1}$ These aneurysms have been classified into two groups according to shape and the texture of the walls and neck: one is "blister type" a small $(\leq 6 \mathrm{~mm})^{2}$ hemispherical bulge with fragile walls, and the other is a saccular type aneurysm. Even though that they occur within the same anatomical regions these two lesion types are distinct. ${ }^{3}$

These aneurysms called blister-like aneurysms (BBA) have unique characteristics: (1) high mortality and morbidity because of a high risk of intraoperative and postoperative rupture; (2) they have extremely fragile walls, making ordinary clipping difficult and hazardous while preserving the parent artery and (3) morphologically, it is small with a broad base and is thus difficult to place coils in the cavity. ${ }^{3-5}$ The clinical features include right-side dominance, female dominance, high incidence in younger patients with $\mathrm{SAH}$, although also BBAs have been described in the pediatric population; ${ }^{6}$ they are associated hypertension, arteriosclerosis or dissection of the ICA..$^{2-4,7,8}$ The aneurysms are generally located anteromedially on the ICA, but several aneurysms arise from other surfaces, such as the anterior, anterolateral walls, medial, posteromedial, and lateral walls of the ICA., ${ }^{3,9}$ In addition, case reports have described BBA from other arteries of the anterior circulation including the anterior communicating artery $(\mathrm{Aco} A)^{10,11}$ and of the vertebral artery or of the posteroinferior cerebellar artery (PICA) have been described previously in the literature. ${ }^{12}$

\section{Etiopathogenesis}

This type of aneurysm does not arise at the arterial divisions and, therefore, an unusual pathogenesis of the aneurysmal formation has been suspected. ${ }^{13}$ Formation of $\mathrm{BBA}$ is assumed to be the result of a break in the equilibrium between hemodynamic stress and the condition of the internal elastic lamina (IEL) and intima. Hemodynamic stress is presumed to be the primary factor causing remodeling, degeneration, and loss of IEL. ${ }^{14} \mathrm{~A}$ report provides a mechanistic explanation for the development of blisters at a specific area; these data demonstrate that BBA are formed within the areas of low shear magnitude and high shear gradient, and suggest that the low shear-associated endothelial dysfunction may trigger the progression of cerebral aneurysms, blister formation results from local weakness of the aneurysm wall and is strongly related to aneurysm rupture. ${ }^{15}$ These findings, in conjunction with ulceration resulting from arteriosclerosis, ${ }^{13}$ and others factors that weaken the structure of IEL, such as inflammation, infection, trauma, congenital factors etc., could be associated with the etiology of BBA. ${ }^{14}$

The histological characteristics of blood blister-like aneurysms include focal wall defects covered with clot and fibrous tissue. ${ }^{13}$ The walls of blood blister-like aneurysms are composed of only normal adventitia, in an abrupt transformation from the sclerotic ICA wall. Disection of the ICA has also been associated for BBA. ${ }^{3,13}$

\section{Diagnostic}

Most cases present with acute SAH and severe clinical conditions. In terms of the imaging modalities, recent advances in computed tomography angiogram (CTA) and digital subtraction angiography (DSA) enable the identification of tiny intracranial aneurysms. CTA and DSA angiography are still the gold standards to evaluate $\mathrm{BBA}^{16}$ and $\mathrm{MR}$ imaging might give additional information for the diagnosis of these lesions. ${ }^{8} \mathrm{BBA}$ appear upon angiography as an aneurysm at a nonbranching site of the supraclinoid ICA in which a rupture is suspected according to the distribution of subarachnoid hemorrhage upon computed tomography (CT) and/or angiographic findings, small hemispheric appearance $<6 \mathrm{~mm}$ of thin aneurysmal wall without a neck with no or minimum pathological findings in the adjacent ICA wall BBAs or signs of dissecting aneurysm. ${ }^{5}$

BBAs are characterized by negative angiographic findings, because of this a meticulous technique and a high index of suspicion are often both necessary to make this diagnosis. ${ }^{3,16}$ The location and small size of the BBA mean that anteroposterior- and lateralview angiography studies provide less complete visualization of these lesions; therefore is recommended performing rotational angiography in cases of suspected BBA. Special attention is required in oblique-view angiography studies, to avoid missing these lesions. ${ }^{4}$ If angiography studies reveal a lesion that might be a $\mathrm{BBA}$, it is preferable to confirm collateral flow from the posterior circulation and the contralateral side via the posterior communicating artery ( $\mathrm{PCoA})$ and ACoA. ${ }^{17}$ This strategy will allow to determine whether the lesion can be trapped if it cannot be clipped because of a possible laceration of the neck. If trapping is considered, it may be useful to perform preoperatively 
a balloon occlusion test for collateral flow. In addition, the external carotid artery should be examined in case it is necessary to perform bypass surgery. Furthermore, the location of the aneurysm in relation to the PCoA and anterior choroidal artery should be determined, because wrapping the full circumference of the ICA or applying an encircling clip may difficult if these arteries are located on either side of the aneurysm. ${ }^{4}$

If initial finding angiographics are negative for a bleeding source a repeat DSA within 2 weeks after the ictus have to be performed, ${ }^{10}$ because of BBAs also exhibit rapid change in size and morphology in follow up angiograms. ${ }^{3,4,17}$

Is extremely difficult in preoperative DSA to determine whether these aneurysms are either saccular or blister-like; thus, angiographic findings did not always correlate with the intraoperative features. Therefore, intraoperative findings are required for the final diagnosis. $3,5,7$

\section{Treatment}

Treatment of BBA remains challenging because of their small size, broad base morphology, and fragile wall. The available treatment options for BBAs are surgical or endovascular treatment. ${ }^{3}$

\section{Surgical treatment}

Surgical decision for BBA should be individual with alternative plans in case the initial treatment strategy fails. Over the years, different treatment strategies have been developed to deal with BBA. Surgical treatment has the advantage of allowing for direct observation of the vascular lesion. Direct surgical approaches include clipping, wrapping, clipping on various wrapping material, suturing, trapping with or without bypass. ${ }^{3,7}$ Clipping, wrapping or trapping alone are associated with inferior outcomes. ${ }^{3}$

Direct clipping of a BBA is reputed to be hazardous due to the high reported incidence of intra and postoperative bleeding. ${ }^{3-5,18}$ Moreover, if clip blades do not catch the wall of the parent artery, rebleeding and aneurysm regrowth will occur. To avoid this result, clipping combined with ICA stenosis has been performed. However, applying a clip that intentionally narrows the ICA reportedly results in severe ischemic complications. ${ }^{3,4}$ Intraoperative rupture has been reported to occur during dissection, while arteries are manipulated, ${ }^{9}$ clip closure when ligation is performed at the thin aneurysm's neck, and following slipping-off of the clip. ${ }^{2,3}$ Such tears have been managed in various ways including trapping, clipping on wrapping material ${ }^{7}$ suturing the tear ${ }^{9,19}$ (8-0 nylon sutures) clipping with encircling clip. ${ }^{9}$ Postoperative rebleeding might result of torsion or slipping-off of the clip, incomplete clipping or rebleeding from a regrowth due to insufficient inclusion of the adjacent wall of the parent vessel between the clip blades.

Some authors have suggested that the best treatment for ruptured BBA is clipping on wrapping material, making sure that the blades are applied parallel to the ICA and they catch the arterial wall beyond the lesion. ${ }^{3,5,18}$ Various wrapping material have been used including gauze, cotton patties, muscle, fascia, transparent silicone sheet ${ }^{19}$ and Gore-Tex. ${ }^{3,9}$ Clipping the bulge on wrapping material does not necessarily completely occlude the aneurysm as the border of the lesions may be difficult to identify through the wrapping material and therefore, may not prevent rebleeding and regrowth of BBA. ${ }^{18,20}$ Cerebral angiography is mandatory because the clip reinforcement technique can cause stenosis of the parent artery or a remnant aneurysm may be present. ${ }^{19}$

Other groups have proposed trapping the involved segment and revascularization if necessary as the most definite treatment method ${ }^{5,20,21}$ If trapping is contemplated, either endovascularly or surgically, careful assessment of the PcoA and its adjacent perforators must be warranted. Surgical trapping has been recommended if BBA extend very close to the origin of the PcoA and adjacent perforators as this option has the best chance of maintaining their patency. ${ }^{5}$ In any case, occlusion of a major vessel during the acute phase of a SAH is associated with a poorer prognosis related to the potential occurrence of cerebral ischemia due to vasospasm. ${ }^{2,5,17}$ For this reason, some have recommended upfront combined EC-IC bypass followed by trapping. ${ }^{20,21}$

Although several surgical strategies are available to treat $\mathrm{BBA}$, the safest treatment modality is still a matter of conjecture.

\section{Endovascular treatment}

Various endovascular strategies have been developed, including coiling with or without assistance of stent or balloon, endovascular trapping, stent-with-stent technique or flow diversion stents.

Given the proposed pathogenesis of BBA, endovascular coiling of the hemispheric tiny bleb is potentially hazardous, with an elevated risk of procedural rupture $(75 \%)$ given the fragility of its wall. ${ }^{17}$ Indeed, despite using softer coils, shaping the microcatheter tip ${ }^{22}$ appropriately or using stent or 
balloon assisted techniques, ${ }^{23}$ endovascular coiling has not provided, in general, satisfactory results. ${ }^{17}$ Packing is often incomplete due to BBA's configuration and results in most instances in persistent flow and residual neck. ${ }^{17,24}$ Because of its inherent technical drawbacks, coiling does not prevent regrowth or rebleed in most instances. ${ }^{17}$ Although coiling does not cure the lesion, it is believed to offer temporarily some protection allowing the ICA to heal overtime. ${ }^{25,26}$

Endovascular trapping has been used for patients who tolerated the BTO. ${ }^{17}$ However, as already mentioned, BTO may be difficult to evaluate in the setting of acute SAH. ${ }^{2,21,25}$ The development of severe vasospasm may compromise collateral circulation resulting in large infarct, even in cases when spontaneous cross flow was present on initial angiography. ${ }^{2}$ Furthermore, trapping, either by surgical trapping or endovascular occlusion, may interfere with endovascular access for delayed vasospasm treatment.

Endovascular techniques using either stents assist coiling (SAC) or stent with stent (SWS) have been attempted. Some authors have tried coiling with SAC technique. ${ }^{11,23}$ Stent placement across the neck of the aneurysm both protects the parent vessel from the herniating coils and potentially permits tighter packing of the aneurysm. However, when using stent protection, safe navigation of the microcatheter through the stent interstices in the lesion may be difficult and is associated with a high risk of aneurysm rupture either during catheterization or subsequent coil placement. ${ }^{11}$ Regrowth and rebleeding is a potential risk, enhanced by the need for perioperative anticoagution/antiplatelet therapy required by the stent. ${ }^{12,24,26}$

The SWS technique attempts to diminish the flow into the aneurysm and decreases the hemodynamic stresses placed upon the lesions through flow diversion. ${ }^{24}$ SWS may double the strut density and thickness of the stent, thus reinforcing blood flow remodeling and arterial wall support. These effects may help reconstruct the fragile neck of the BBA and prevent its regrowth ${ }^{24}$ and also because of this measure would accelerate aneurysm thrombosis and healing. ${ }^{27}$ Advantageously, it allows for parent artery preservation with reduction on the risk of subsequent stroke development. This technique is challenging as the second stent may become inadvertently entrapped in the cells of the first, preventing proper deployment of the second stent and poor apposition to the wall of the vessel. Very early angiographic follow-up is recommended to assess for any regrowth and complementary aneurismal treatment. ${ }^{16}$

Some have proposed the use of covered stents (stent-grafts) to treat a focal weakness of the arterial wall. ${ }^{11}$ Such devices are however stiff and difficult to navigate to the appropriate location along the ICA bend, resulting in failure of the aneurysm sealing ${ }^{27}$ Current experience with such stents is limited. ${ }^{24}$ Placement of a covered stent may not be feasible if normal PcoA and anterior choroidal artery are arising from the diseased arterial segment.

It is expected the development of new stent technology that promotes vascular neointima formation and generates less platelet activation and aggregation ${ }^{25}$ Novel Silk flow-diverting (SFD) $)^{28,29}$ and Pipeline embolization device (PED) ${ }^{12}$ have been used in the treatment of BBA successfully; these devices form a scaffold upon which endothelial regrowth can occur, leading to the full coverage of the implant and the aneurysm neck. However, other reports have indicated that its use in the context of acute subarachnoid hemorrhage (SAH) should be cautioned because of a relatively high rate of rebleeding. ${ }^{30}$ Flow-diverting devices represent an important advancement in the treatment of BBA, so that larger studies and long-terms results are necessary. ${ }^{28,29}$

\section{Conclusion}

BBA of ICA are rare vascular lesions, preoperative recognition is essential for proper management, because of they are associated with a high morbidity and mortality rate. Unfortunately, there is currently no solid evidence supporting one treatment strategy over another, therefore decision of treatment for BBA should be individual with alternative plans in case the initial treatment strategy fails to obtain the best outcome for the patient.

\section{References}

1. Yasargil MG. Microneurosurgery: clinical considerations, surgery of the intracranial aneurysms and results. Stuttgart: Georg Thieme; 1984.

2. Meling TR, Sorteberg A, Bakke SJ, Slettebø $H$, Hernesniemi $\mathrm{J}$, Sorteberg W. Blood blister-like aneurysms of the internal carotid artery trunk causing subarachnoid hemorrhage: treatment and outcome. J Neurosurg. 2008;108(4):662-71.

3. Ogawa A, Suzuki M, Ogasawara K. Aneurysms at nonbranching sites in the surpaclinoid portion of the internal carotid artery: internal carotid artery trunk aneurysms. Neurosurgery. 2000;47(3):578-83.

4. Sim SY, Shin YS, Cho KG, Kim SY, Kim SH, Ahn YH, et al. Blood blister-like aneurysms at nonbranching sites of the internal carotid artery. J Neurosurg. 2006;105(3):400-5.

5. Shimizu H, Matsumoto $\mathrm{Y}$, Tominaga T. Non-saccular aneurysms of the supraclinoid internal carotid artery 
trunk causing subarachnoid hemorrhage: acute surgical treatments and review of literatures. Neurosurg Rev. 2010;33(2):205-16.

6. Haji FA, Boulton MR, de Ribaupierre S. Blister-like supraclinoid internal carotid artery pseudoaneurysm in a 15-year-old male: case report and review of the literature. Pediatr Neurosurg. 2011;47(6):449-54.

7. Otani N, Takasato Y, Masaoka H, Hayakawa T, Yoshino $\mathrm{Y}$, Yatsushige $\mathrm{H}$, et al. Clinical and radiological finding and surgical management of ruptured aneurysms at the nonbranching sites of the internal carotid artery. J Clin Neurosci. 2009;16(8):1018-23.

8. Horie N, Morikawa M, Fukuda S, Hayashi K, Suyama K, Nagata I. Detection of blood blister-like aneurysm and intramural hematoma with high-resolution magnetic resonance imaging. J Neurosurg. 2011;115(6):1206-9.

9. Yanaka K, Meguro K, Nose T. Repair of a tear at the base of a blister-like aneurysm with suturing and an encircling clip: technical note. Neurosurgery. 2002;50(1):218-21.

10. Andaluz N, Zuccarello M. Blister-like aneurysms of the anterior communicating artery: a retrospective review of diagnosis and treatment in five patients. Neurosurgery. 2008;62(4):807-11.

11. Ahn JY, Cho JH, Jung JY, Lee BH, Yoon PH. Blister-like aneurysms of the supraclinoid internal carotid artery: challenging endovascular treatment with stent-assisted coiling. J Clin Neurosci. 2008;15(9):1058-61.

12. Consoli A, Nappini S, Renieri L, Limbucci N, Ricciardi F, Mangiafico S. Treatment of two blood blister-like aneurysms with flow diverter stenting. Neurointerv Surg. 2012;4(3):e4.

13. Ishikawa T, Nakamura N, Houkin K, Nomura M. Pathological consideration of a "blister-like" aneurysm at the superior wall of the internal carotid artery: case report. Neurosurgery. 1997;40(2):403-5.

14. Mizutani T, Kojima H. Clinicopathological features of non-atherosclerotic cerebral arterial trunk aneurysms. Neuropathology. 2000;20(1):91-7.

15. Shojima M, Nemoto $S$, Morita A, Oshima M, Watanabe E, Saito N. Role of shear stress in the blister formation of cerebral aneurysms. Neurosurgery. 2010;67(5):1268-74.

16. Gaughen JR Jr, Raghavan P, Jensen ME, Hasan D, Pfeffer AN, Evans AJ. Utility of CT angiography in the identification and characterization of supraclinoid internal carotid artery blister aneurysms. AJNR Am J Neuroradiol. 2010;31(4):640-4.

17. Park JH, Park IS, Han DH, Kim SH, Oh CW, Kim JE, et al. Endovascular treatment of blood blister-like aneurysms of the internal carotid artery. J Neurosurg. 2007;106(5):812-9.

18. Lee JW, Choi HG, Jung JY, Huh SK, Lee KC. Surgical strategies for ruptured blister-like aneurysms arising from the internal carotid artery: a clinical analysis of 18 consecutive patients. Acta Neurochir (Wien). 2009;151(2):125-30.

19. Joo SP, Kim TS, Moon KS, Kwak HJ, Lee JK, Kim JH, et al. Arterial suturing followed by clip reinforcement with circumferential wrapping for blister-like aneurysms of the internal carotid artery. Surg Neurol. 2006;66(4):424-8.

20. Kawashima A, Okada Y, Kawamata T, Onda H, Kubo O, Hor T. Successful treatment of a blood blister-like aneurysm of the internal carotid artery by trapping with a high-flow bypass. J Clin Neurosci. 2008;15(7):797-800.

21. Başkaya MK, Ahmed AS, Ateş O, Niemann D. Surgical treatment of blood blister-like aneurysms of the supraclinoid internal carotid artery with extracranial-intracranial bypass and trapping. Neurosurg Focus. 2008;24(2):E13.

22. Doorenbosch $X$, Harding M. Primary treatment of a bloodblister-like aneurysm of the internal carotid artery with Guglielmi detachable coil embolisation. J Clin Neurosci. 2008;15(11):1276-9.

23. Kim BM, Chung EC, Park SI, Choi CS, Won YS. Treatment of blood blister-like aneurysm of the internal carotid artery with stent-assisted coil embolization followed by stent-within-a-stent technique. Case report. J Neurosurg. 2007;107(6):1211-3.

24. Lee BH, Kim BM, Park MS, Park SI, Chung EC, Suh SH, et al. Reconstructive endovascular treatment of ruptured blood blister-like aneurysms of the internal carotid artery. J Neurosurg. 2009;110(3):431-6.

25. Matsubara N, Miyachi S, Tsukamoto N, Izumi T, Naito T, Haraguchi K, et al. Endovascular coil embolization for saccular-shaped blood blister-like aneurysms of the internal carotid artery. Acta Neurochir (Wien). 2011;153(2):287-94.

26. Fang YB, Li Q, Yang PF, Huang QH, Zhao WY, Xu Y, et al. Treatment of blood blister-like aneurysms of the internal carotid artery with stent-assisted coil embolization. Clin Neurol Neurosurg. 2013;115(7):920-5.

27. Kim YW, Park IS, Baik MW, Jo KW. Endovascular treatment of blood blister-like aneurysms using multiple self-expanding stents. J Korean Neurosurg Soc. 2011;49(2):116-9.

28. Causin F, Pascarella R, Pavesi G, Marasco R, Zambon $\mathrm{G}$, Battaglia R, et al. Acute endovascular treatment $(<48$ hours) of uncoilable ruptured aneurysms at non-branching sites using silk flow-diverting devices. Interv Neuroradiol. 2011;17(3):357-64.

29. Princiotta C, Dall'olio M, Cirillo L, Leonardi M. Staged treatment of a blood blister-like aneurysm with stentassisted coiling followed by flow diverter in-stent insertion. A case report. Interv Neuroradiol. 2011;17(3):365-70.

30. Leung GK, Tsang AC, Lui WM. Pipeline embolization device for intracranial aneurysm: a systematic review. Clin Neuroradiol. 2012;22(4):295-303.

Correspondence address

Eberval Gadelha Figueiredo

Division of Neurosurgery of

Hospital das Clínicas,

University of São Paulo

Rua Dr. Enéas Carvalho Aguiar, 255

05403-123 - São Paulo, SP, Brazil 